\title{
Towards A Unified Identification of Ti Location in the MFI Framework of High-Ti-Loaded TS-1: A Combined EXAFS, XANES, and DFT Study
}

Juncai Dong, ${ }^{1, \S}$ Hailiang Zhu, ${ }^{1, \S}$ Yanjuan Xiang, ${ }^{2}$ Yan Wang, ${ }^{1}$ Pengfei An, ${ }^{1}$ Yu Gong, ${ }^{1}$

Yaxiang Liang, ${ }^{1}$ Limei Qiu, ${ }^{2}$ Aiguo Zheng, ${ }^{2}$ Xinxin Peng, ${ }^{2}$ Min Lin, ${ }^{2}$ Guangtong Xu, ${ }^{2, *}$

Zhiying Guo, ${ }^{1, *}$ Dongliang Chen ${ }^{1, *}$

${ }^{1}$ Beijing Synchrotron Radiation Facility, Institute of High Energy Physics, Chinese

Academy of Sciences, Beijing 100049, China

${ }^{2}$ State Key Laboratory of CatalyticMaterial and Reaction Engineering, Research Institute of Petroleum Processing, SINOPEC, Beijing 100083, China

\section{Corresponding Author}

*xugt.ripp@sinopec.com

*zyguo@ihep.ac.cn

*chend1@ihep.ac.cn; Tel: +86-10-88235156

\section{Author Contributions}

$\S$ These authors contributed equally. 


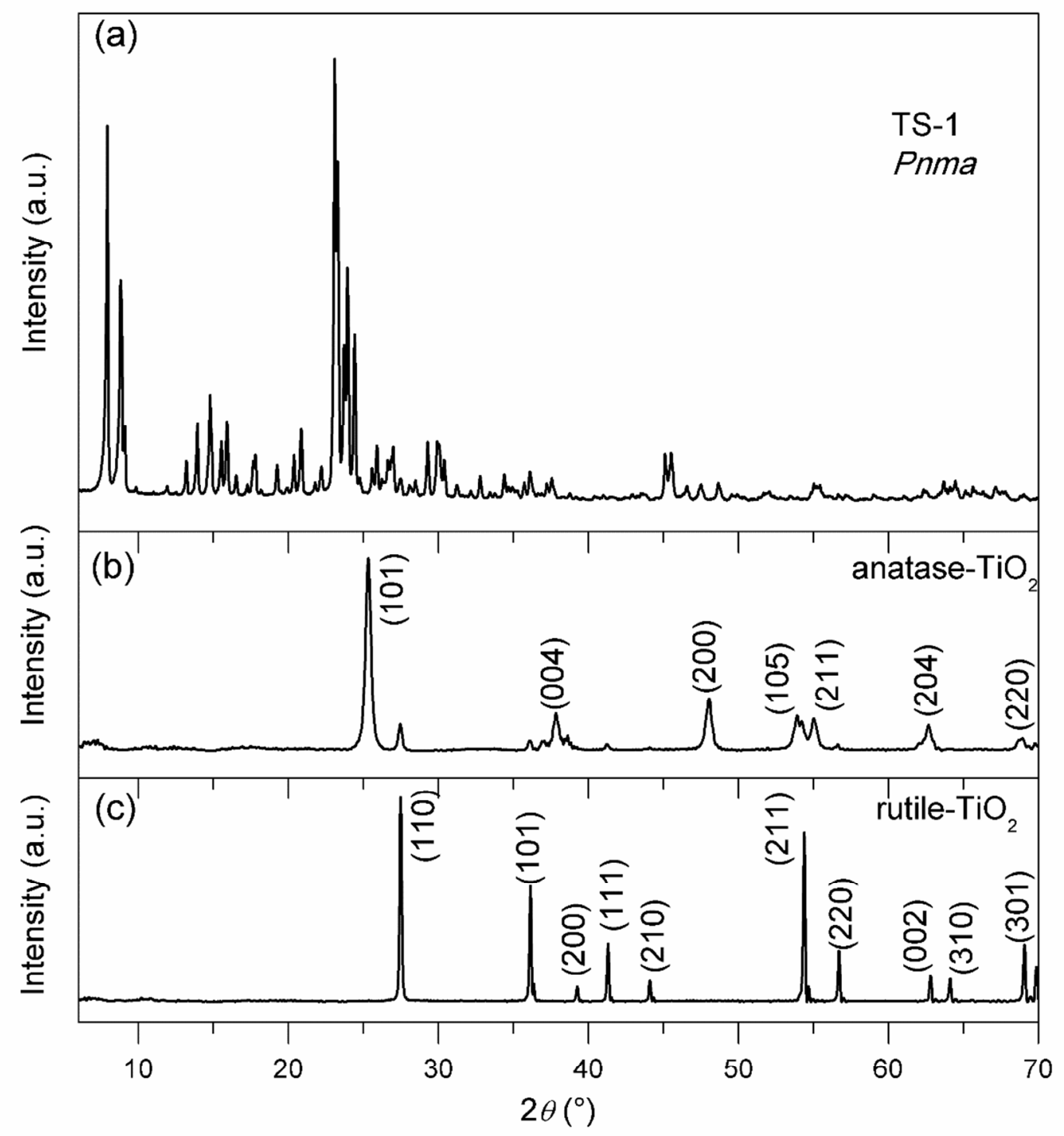

Supplementary Figure 1. X-ray diffraction patterns of the TS-1, anatase $\mathrm{TiO}_{2}$ and rutile $\mathrm{TiO}_{2}$. 